\title{
Dimensões socioambientais do rural contemporâneo
}

\section{Socio-environmental dimensions of contemporary rurality}

\author{
Alfio BRANDENBURG* \\ Angela Duarte Damasceno FERREIRA** \\ Leonardo José Cordeiro SANTOS ${ }^{* * *}$
}

\begin{abstract}
RESUMO
O texto trata do meio ambiente rural da Região Metropolitana de Curitiba e do Litoral Norte do Paraná a partir da sua heterogeneidade, do rural como espaço de interesses ambientais conflitantes, como espaço do risco socialmente construído, como espaço de reencontro com a natureza e como espaço de surgimento de novos atores sociais. Em função dos processos organizativos em curso nos espaços rurais, e em função do reconhecimento da diversidade de situações socioambientais existentes e das distintas estratégias implementadas pelos diferentes atores para se reproduzir, pode-se dizer que existe uma vitalidade dos grupos sociais rurais para recriar suas trajetórias e inscrevê-las como elementos da historicidade do seu território .

Palavras-chave: rural, heterogeneidade, sociedade, ambiente, agricultura.
\end{abstract}

\begin{abstract}
The text addresses the rural environment in the Curitiba Metropolitan Area and in Paraná's northern coastal area in its heterogeneity, rural area as a space of conflicting environmental interests; as a space of socially created risk; as a space of reencounter with nature; and as a space for the emergence of new social actors. Owing to the organizational processes that are taking place in rural areas, and as a function of acknowledging the diversity of existing socio-environmental situations and different strategies implemented by different actors to reproduce themselves, it can be said that there is vitality in the rural social groups as they recreate their trajectories and include them as elements of the history of their territory.

Key-words: rural, heterogeneity, society, the environment, agriculture.
\end{abstract}

* Professor do Depto de Ciências Sociais, Mestrado em Sociologia e Doutorado em Meio Ambiente e Desenvolvimento/UFPR

** Professora da UFPR- Doutorado em Meio Ambiente e Desenvolvimento e Programa de Pós-Graduação em Sociologia.

*** Professor do Depto. de Geografia, Mestrado em Geografia e Doutorado em Meio Ambiente e Desenvolvimento UFPR. 
As reflexões aqui apresentadas têm como referência empírica estudos desenvolvidos na Região Metropolitana de Curitiba e Litoral Norte do Paraná, no contexto da linha de pesquisa Ruralidades, Ambiente e Sociedade do Doutorado em Meio Ambiente e Desenvolvimento da UFPR. Participam dessa linha um grupo de pesquisadores (docentes, doutorandos e mestrandos) do próprio doutorado, do Mestrado em Sociologia da UFPR e de duas universidades francesas (Bordeaux 2 e Paris 7). São pesquisadores de formação diversa, com domínios de conhecimento nas áreas de ciências sociais e naturais, constituindo uma equipe de formação para estudos interdisciplinares. O texto trata do meio ambiente rural a partir dos seguintes aspectos: heterogeneidades do rural; o rural como espaço de interesses ambientais conflitantes; como espaço do risco socialmente construído; como espaço de reencontro com a natureza e como espaço de surgimento de novos atores sociais.

Tratar do rural e meio ambiente no Brasil implica em reconhecer que existem vários rurais, isto é, ruralidades de tempos diferentes. Nesse sentido, existe ainda no Brasil um rural do tempo que antecede a modernização intensiva, o qual denominamos rural tradicional, um rural moderno e um rural da modernidade crítica, ou reflexiva.

Este rural diverso coexiste muitas vezes num mesmo espaço social e geográfico, o que torna complexo estudar o rural em um só tempo. Não vamos nos deter aqui - pela limitação de espaço - na caracterização desses diversos rurais uma vez que tanto o rural tradicional quanto o rural moderno já são bastante conhecidos e continuam sendo estudados pelos pesquisadores de diversas áreas do conhecimento. É do rural da segunda fase da modernidade que vamos tratar, um rural onde o meio ambiente emerge como questão relacionada com a reprodução da vida social e natural dos atores sociais e, por isso, incorporado no plano das políticas públicas e nas estratégias de ação dos agricultores, constituindo opções, alternativas de ações sociais, portanto, fruto de uma decisão reflexiva.

O rural da segunda fase da modernidade pode ser definido como o de sua reconstrução, de sua reflexividade ou de sua destruição criativa, para utilizar os conceitos Beck e Giddens (1998). A tradição que na modernidade deveria ser ultrapassada e a natureza que deveria ser vencida passam a ser ressignificadas e revalorizadas na modernidade avançada. O avanço unilateral da racionalidade técnica sobre os modos de vida do meio rural passa a ser questionada pelos movimentos sociais alternativos ou ambientalistas, e o conhecimento e a técnica industrial pas- sam a não ser os únicos instrumentos de mediação homemnatureza.

A reconstrução do rural traz implicitamente uma lógica de articulação com a sociedade e o ambiente que não se resume a reproduzir valores e uma lógica hegemônica do industrialismo urbano. Há uma relação entre os mundos rural e urbano, em que, de um lado, o rural assume a condição da materialidade e dos ideais da vida urbana, de outro, a sociedade resgata formas de vida social e de relação com a natureza, cuja referência está no campo e numa certa continuidade de uma condição de uma vida camponesa (WANDERLEY, 1996). É nesse sentido que podemos falar que na sociedade e também no meio rural assistimos a uma espécie de reencantamento do mundo.

A industrialização dos processos produtivos na agricultura não exclui a gestão de recursos naturais de produção. Desta forma a agricultura não caminha necessariamente para as condições de artificialização absoluta da produção. As relações sociais não articulam valores e interesses exclusivamente urbanos e nem reduzem os personagens do meio rural à condição de agentes passivos ou de objetos de um sistema.

É nessa dimensão temporal da ruralidade que abordaremos alguns aspectos, que são próprios da contemporaneidade e que são por isso considerados nos programas de pesquisa.

\section{Heterogeneidade}

A modernização da agricultura não levou a um processo de homogeneização do rural no que tange aos seus aspectos, sociais, produtivos, técnicos, biológicos, espaciais e cognitivos. Nesse sentido um primeiro aspecto a ser considerado é a heterogeneidade do espaço sócio-geográfico. $\mathrm{Na}$ Região Metropolitana de Curitiba constatamos que existem vários rurais. Os indicadores nos mostram existirem municípios que servem apenas de espaço de residência para os que trabalham na capital - são cidades dormitórios. Outros, em contínuo esvaziamento da população rural, estão se urbanizando ou se industrializando, e outros, contradizendo a lógica aparente do esvaziamento do rural da região metropolitana, têm um aumento expressivo do número de agricultores familiares e, desta forma, tanto cresce a população rural como permanece ou reaparece a agricultura como atividade principal. Estamos assim diante de um rural com espaços ocupados de formas diferenciadas (WANDERLEY, 2002). 
No que se refere aos padrões de organização social e produtiva, temos que considerar que os estudos de mudança tecnológica já não apontam necessariamente para substituição de práticas tradicionais por práticas de insumos industriais e tampouco para uma universalização dessas práticas. Como o ambiente passa a ser uma referência na reorganização sociotécnica da agricultura, as práticas ecológicas que incorporam o manejo de recursos naturais passam a ser consideradas nas escolhas técnicas (ALMEIDA, 2003).

Os sistemas de produção agrícola são reorganizados de forma a conservar a diversidade biológica, considerando a reprodução da vida do agricultor e do sistema natural mesmo nos sistemas convencionais de produção agrícola (BATISTA DA COSTA, 2004). Desta forma, estes sistemas de produção, organizados de forma diversa, estão associados a dimensões de caráter social e natural.

$\mathrm{O}$ ambiente natural muitas vezes se impõe de forma restritiva à agricultura, ou incita a buscar modelos e práticas alternativas em função do papel que as áreas rurais são demandadas a assumir. Na Região Metropolitana de Curitiba por exemplo, as áreas de mananciais têm um papel importante no fornecimento de água potável. Nesse caso, ou se restringe a prática de uma agricultura convencional ou se estimulam modelos ecológicos de produção. O mesmo vale para as Áreas de Proteção Ambiental de Guaraqueçaba, Litoral Norte do Paraná.

A dimensão físico-biológica é muitas vezes determinante no uso e ocupação do espaço natural, assim como é frequentemente é impactada por usos que não correspondem às suas potencialidades ou por restricões advindas de políticas de conservação dos recursos naturais.

No caso da Região Metropolitana de Curitiba, os estudos demonstram a existência de quatro grandes domínios naturais que se associam a diferentes usos e ocupação do solo, formas de relação sociedade-natureza, nível tecnológico e padrões de vida, cuja interação merece ser melhor investigado (DIAS; SANTOS, 2004):

1) nos municípios localizados no domínio 1 (Ex: São José dos Pinhais, Campina Grande do Sul, Quatro Barras), apesar da produção agrícola intensiva e do alto uso de tecnologia e boas condições de vida, existem restrições de uso do solo pela proximidade da Serra do Mar que elevam os riscos de movimentos de massa, além da presença de unidades de conservação;
2) nos municípios localizados no domínio 2 (Ex: Dr. Ulysses, Adrianópolis, Tunas do Paraná, Cerro Azul), com produção agrícola extensiva, baixo nível tecnológico e precárias condições de vida, existem restrições impostas pelo relevo acidentado, solos rasos e pouco férteis, pressionados ainda pelas áreas de restrição ambiental;

3) outro grupo de municípios que apresenta significativo conflito sociedade/natureza é aquele que se situa na região kárstica (Ex: Itaperuçu, Rio Branco do Sul, Almirante Tamandaré e Colombo) pela fragilidade do meio físico, rochas calcáreas, o que implica em restrições ao uso e ocupação do solo, o que pode ser agravado pela possibilidade do Aqüífero Karste ser incorporado aos mananciais de abastecimento da metrópole;

4) por último, há um grupo de municípios (Ex: Lapa, Balsa Nova, Contenda, Araucária) onde concentra-se a produção intensiva de batata, cebola e grãos, com alta tecnologia associada a solos férteis, mas que estão sujeitos à erosão em função do uso intensivo de insumos e tecnificação.

No caso do litoral paranaense, os estudos de OkaFiori e Canali (1998), apontam para a existência de três compartimentos: compartimento de serras e morros, compartimento das planícies e compartimento dos mangues.

As serras e morros caracterizam-se pelas altas elevações, com topos e cristas alongadas, vertentes íngremes e solos rasos. Apresentam grande instabilidade natural à ocorrência de movimentos de massa em virtude das características do meio físico já mencionadas, associadas às altas precipitações. A vegetação natural é a floresta ombrófila densa e a sua retirada pode aumentar a instabilidade do compartimento. São áreas não apropriadas para a agricultura mas que sofrem com o impacto de atividades extrativistas.

O compartimento das planícies, formado por sedimentos de origem litorânea e/ou fluvial, caracteriza-se pela suavidade do relevo, pelas baixas declividades e pelos solos mais profundos. Essas condições do meio físico favorecem a sua ocupação e a sua exploração agrícola, entretanto, a presença de lençol freático aflorante, principalmente nas proximidades das drenagens, restringe o uso do solo. Ali situamse as áreas agrícolas da região mas sua fragilidade requer cuidados e restrições. Recentemente, há um processo de reconversão para a agricultura ecológica que implica em manejos mais adequados à realidade do meio físico da região. 
O compartimento dos mangues localiza-se próximo às baías litorâneas, os solos são salinos e o compartimento está sujeito à ação dos fluxos e refluxos das marés, o que lhe confere características alagadiças e pantanosas. Por suas características e por se constituir em área de proteção ambiental, é vedada a sua ocupação. Mesmo com tais restrições, usos sustentáveis do mangue pelas populações locais estão sendo implantados.

Tomar esta heterogeneidade físico-biológica e social como ponto de partida e pressuposto do estudo dos espaços rurais da Região Metropolitana de Curitiba e do Litoral Norte do Paraná, procurando identificar suas especificidades e as inter-relações entre as diferentes dimensões do ambiente rural, tem sido a tarefa primordial dos trabalhos conduzidos pelo Doutorado MADE. Tratase de um esforço para evidenciar empiricamente a falácia do modelo modernizador tanto no seu pressuposto da homogeneização do rural, como na sua pretensão de excluir de qualquer importância agrícola as áreas rurais cujas caracteristicas físico-biológicas propiciassem a implantação do padrão tecnológico e produtivo moderno-convencional.

\section{O rural como espaço de interesses ambientais conflitantes}

Se antes os conflitos convencionais abrangiam a agricultura - indústria, empresários - trabalhadores, grandes proprietários x pequenos agricultores familiares, a questão ambiental trouxe uma nova modalidade de conflito sem excluir as já existentes. A literatura, de modo geral, reconhece que o rural é demandado para assumir funções sociais, tais como a de conservar a natureza, de proporcionar espaço de lazer, promover o abastecimento alimentar, entre outras (MALUF; CARNEIRO, 2002). Estas novas funções que passam a ser desempenhadas pelo rural nem sempre são consensuais e de interesse direto dos agricultores.

Ao refletir sobre a questão ambiental no meio rural, em particular na agricultura, Jollivet (1992) observa que a biodiversidade, o ar, a paisagem, a água, são componentes fundamentais para serem analisados. Nesse aspecto se observa que a água, questão crucial do século 21 , é um dos problemas não somente para as cidades mas também para o campo. O agricultor deve praticar uma agricultura não poluente para não contaminar rios ou lençol freático, conservar florestas e áreas ribeirinhas, planejar matas ciliares e desta forma muitas vezes é forçado a reduzir sua área destinada à produção agrícola para garantir o abastecimento das cidades e, no caso brasileiro, sem uma contrapartida que o possa compensar economicamente.

Nesse aspecto, um caso de fonte de fornecimento de água para a RMC (Região Metropolitana de Curitiba) pode ser tomado como emblemático, como gerador de conflitos entre orgãos públicos e agricultores.

O Aquífero de Karst, localizado no Município de Colombo, na Região Metropolitana de Curitiba, é habitado por agricultores familiares que ali vivem e desenvolvem atividades para o seu sustento. A drenagem de água subterrânea vem prejudicando os agricultores à medida em que os riachos começar a secar e a terra vem cedendo, formando sulcos que afetam construções e impedem o cultivo de suas terras (MILANI, 2003)

As áreas de preservação ambiental, em que pese argumentos científicos fortes sobre a necessidade de sua conservação, afetam diretamente os interesses dos agricultores, em especial a reprodução social dos agricultores familiares (ZANONI et al., 2000). Estes casos, como bem mostraram as teses realizadas sobre Guaraqueçaba, litoral norte do Paraná, mostram como a proteção ambiental, tal como tem sido realizada em muitos espaços brasileiros, pode se contrapor a um desenvolvimento rural - ou mesmo territorial - que contemple as necessidades das populações locais, gerando conflitos de uso dos recursos e de significados sobre o que é a preservação da natureza, e abrindo caminho para um ambiente rural gerido por mecanismos de fiscalização e repressão.

\section{O rural como espaço do risco socialmente construído}

A industrialização dos processos produtivos gera riscos produzidos no meio urbano e rural. Se antes o meio rural era espaço natural de produção em um ambiente despoluído, livre de resíduos e ruídos típicos do meio urbano-industrial, com a modernização das atividades agrícolas, a intervenção nos processos produtivos apresenta resultados que se traduzem em alerta tanto para o agricultor como para a sociedade.

Este alerta se expressa no desmatamento descontrolado; na simplificação dos sistemas ecológicos; na poluição do solo, da água e do ar; no resíduo tóxico que os agroquímicos deixam dos alimentos; na intensificação dos 
processos de trabalho que leva o agricultor ao limite de sua resistência. A intoxicação, o stress social, agora atingem também o homem do campo. Estudos com agricultores na Região Metropolitana de Curitiba (KARAN, 2001) mostram um agricultor depressivo, intoxicado e por isso disposto a reorganizar os processos produtivos em base ecológica. $\mathrm{Na}$ avaliação dos agricultores, os riscos da tecnologia, principalmente no caso dos agrotóxicos, é percebido mais diretamente na alteração de seu estado de saúde. Esta tem sido uma das razões fortes tanto para os agricultores optarem por técnicas e saberes ambientais, como para os consumidores optarem por uma alimentação ecológica (DAROLT; KARAN, 2001; PINHEIRO, 2004; RUCINSKI, 2002).

Em função do apelo contemporâneo em favor de uma alimentação limpa, livre de riscos para a saúde, muitos nichos de mercado se abrem para os agricultores que optam por uma agricultura ecológica. Tanto os produtores de olerícolas da RMC como os produtores de banana in natura ou processada do litoral norte do Paraná estão se beneficiando do crescimento de mercados para seus produtos não convencionais e isto tem gerado vários processos paralelos de organização e de certificação participativa, com efeitos de disseminação da proposta ecológica no meio rural onde atuam.

\section{O rural como espaço de reencontro com a natureza}

A natureza é hoje cultivada através de diferentes formas de gestão tendo como base diferentes projeto de vida. Essa diversidade está relacionada a grupos e categorias sociais distintas que procuram investir no rural como uma opção de reconstrução de projetos de vida também distintos. Incluem-se nessa categoria, os chamados neo-rurais que advêm de distintas origens profissionais do meio urbano e descendentes de agricultores e de agricultores familiares (KARAN, 2002; PINHEIRO, 2004).

O projeto de vida dos neo-rurais, ou dos agricultores que constróem uma agricultura ambientalizada ou ecológica, é fruto de uma decisão de mudança nos padrões de ação e conduta desses personagens que foram profundamente marcados pelo processo de modernização. São críticos da modernidade e encontram no rural uma forma de reconstruir a sua vida, reconstruindo a natureza exterior e ao mesmo tempo suas próprias subjetividades. Não raras às vezes, transformam-se em militantes e protagonistas de movimentos sociais ambientalistas (BALASTRINI, 2002).

\section{O rural como espaço de surgimento de novos atores sociais}

O rural está sendo reconstruído com a participação de novos atores sociais, cujo papel deve ser compreendido e analisado tendo em vista a formulação de políticas públicas que levem em conta os interesses e o contexto socioambiental desses atores.

Quem são esses novos atores, qual seu significado? Definimos como novos atores aqueles que articulam novas formas de relação com a natureza com novas formas de relação social, contrapondo-se, desta forma, a formatos hegemônicos de produção e organização. Nesse sentido, as práticas agrícolas mediadoras da relação com a natureza são orientadas pela gestão dos recursos naturais ao invés de privilegiar processos cujos componentes são os agroquímicos e outros artefatos industrializados. São práticas de gestão que incluem saberes de domínio dos agricultores, constantemente em recriação em função de suas cambiantes condições socioambientais. São formas de gestão que, ao privilegiar a preservação dos recursos naturais, atenuam a pressão sobre a natureza induzida pela sua artificialização. Esse modo de gestão, cujo processo situa o agricultor na condição de ator, está associado a formas de organização social - como associações e feiras e redes de comercialização -, cujos processos permitem ao agricultor expressar-se nas várias dimensões de sua individualidade e construir projetos referenciados por movimentos coletivos. Pode-se identificar, nessa reconstrução da relação com a natureza e da relação social, uma confluência de processos relacionados com a reprodução da vida, tanto natural quanto humana. Tanto no caso do agricultor quanto de outro ator social, esse processo de reencontro com a natureza só pode ser experimentado quando na condição de sujeito. Esta é a razão por que são consideradas alternativas às práticas convencionais, porque resistem a heteronomia e às práticas instrumentalizadoras. Esta mudança mais ampla, que não inclui apenas uma adoção de novas práticas agrícolas, é amplamente identificada nos vários estudos que abordam a agricultura ecológica ou alternativa (DAROLT; KARAN, 2001; BALESTRINI, 2002; PINHEIRO, 2004.)

Sem pretender recuperar a história do movimento alternativo e ambiental na agricultura, apenas realçamos a importância desse movimento na reconstrução de um rural ecológico ou socioambiental. Pode-se citar a título de exem- 
BRANDENBURG, A. et al. Dimensões sociambientais do rural contemporâneo

plo alguns desses atores emergentes nas regiões estudadas: a Associação de Produtores Agrícolas de Colombo-APAC; Associação de Agricultores Orgânicos do Paraná-AOPA; Associações de Turismo Rural (Colombo); Associações de Agricultores de Assentamentos Rurais; Grupos Organizados por local ou comunidades que participam da Rede Ecovida de Ecologia.

É em função destes processos organizativos em curso nos espaços rurais, em função do reconhecimento da diversidade de situações socioambientais existentes e das distintas estratégias implementadas pelos diferentes atores para reproduzir, transformando, a vida e o ambiente diante de tais situações, que se está falando, neste Doutorado, em reconstrução do rural e da ruralidade e em outras agriculturas, noções que põem em evidência a vitalidade dos grupos sociais rurais para recriar suas trajetórias e inscrevê-las como elementos da historicidade do seu território.

\section{REFERÊECIAS}

ALMEIDA, Luciano. Mudanças técnicas na agricultura: perspectivas da transição agroambiental em Colombo, PR. Curitiba, 2003. Tese (Doutorado em Meio ambiente e

Desenvolvimento) - Universidade Federal do Paraná.

BALESTRIN, Nadia Luzia. Associação de Agricultura Orgânica do Paraná: uma proposta em (re)construção. Curitiba, 2002. Dissertação (Mestrado em Sociologia das Organizações) - Universidade Federal do Paraná.

BAPTISTA DA COSTA, Manoel Baltasar. Análise da sustentabilidade da agricultura da Região Metropolitana de Curitiba pela ótica da agroecologia. Curitiba, 2004. Tese (Doutorado em Meio ambiente e Desenvolvimento) - Universidade Federal do Paraná.

BECK, Ulrich; GIDDENS, Anthony; LASH, Scott. Modernização Reflexiva. São Paulo: Unesp, 1997.

CARNEIRO, Maria José. Multifuncionalidade da agricultura e ruralidade: uma abordagem comparativa. In: MOREIRA, José Roberto; CARVALHO COSTA, Luiz Flávio de. (Org.). Mundo Rural e Cultura. Rio de Janeiro: Mauad, 2002.

DAROLT, Moacir R. As dimensões da sustentabilidade: um estudo da agricultura orgânica na região metropolitana de Curitiba, Paraná. Curitiba, 2000. Tese (Doutorado em Meio Ambiente e Desenvolvimento) - Universidade Federal do Paraná, Université Paris 7.

DIAS, J. B.; SANTOS, L. J. C. Aspectos geomorfológicos e o diagnóstico socioambiental do meio rural da região metropolitana de Curitiba. In: SIMPÓSIO BRASILEIRO DE GEOMORFOLOGIA, 5., 2004, Santa Maria, RS. Anais... 2004.
JOLLIVET, Marcel. Agriculture e environnement: reflexions sociologiques. Economie Rurale. Paris: Societé Francçaise d'Economie Rurale, n. 209, p. 5-11, mars/juin 1992.

KARAN, Karen. Agricultura orgânica: estratégia para uma nova ruralidade na região metropolitana de Curitiba. Curitiba, 2001. Tese (Doutorado em Meio Ambiente e Desenvolvimento) - Universidade Federal do Paraná.

MALUF, Renato. Produtos agroalimentares, agricultura multifuncional e desenvolvimento territorial no Brasil. In: MOREIRA, José Roberto; CARVALHO COSTA, Luiz Flávio de. (Org.). Mundo Rural e Cultura. Rio de Janeiro: Mauad, 2002 .

MILANI, Neusa Falcade. A exploração do aquifero de Karst: alterações no cotidiano dos agricultores de Água Fervida, Colombo, PR. Curitiba, 2003. Trabalho acadêmico (Graduação em Ciências Sociais) - Setor de Ciências Humanas, Letras e Artes, Universidade Federal do Paraná.

OKA FIORI, C.; CANALI, N. E. Análise morfométrica de bacias hidrográficas. In: Meio ambiente e desenvolvimento do litoral do Paraná: diagnóstico. Curitiba: UFPR, 1998.

PINHEIRO, Gustavo Silveira Rosa. Agricultores familiares e projeto agroecológico de vida. Curitiba, 2004. Dissertação (Mestrado em Sociologia) - Universidade Federal do Paraná.

RUCINSKI, Jeane. ACOPA: uma associação em construção. Curitiba, 2003. Dissertação (Mestrado em Sociologia) - Universidade Federal do Paraná.

WANDERLEY, Maria de Nazareth Baudel. Raízes históricas do campesinato brasileiro. In: ENCONTRO ANUAL DA ANPOCS, 1996. 
BRANDENBURG, A. et al. Dimensões sociambientais do rural contemporâneo

A valorização da agricultura familiar e a reivindicação da ruralidade. Desenvolvimento e Meio Ambiente, Curitiba: UFPR, n. 2, 2000.
ZANONI, Magda et al. Preservação da natureza e desenvolvimento rural. Desenvolvimento e Meio Ambiente, Curitiba: UFPR, n. 2, 2000. 